\title{
A Model for Evaluating Teaching Effectiveness in Accounting Professional Programmes: A Study from Nigeria
}

\author{
Oyewo Babajide
}

ACA, ACMA (UK), CGMA, Department of Accounting, Covenant University, Ota, Ogun State, Nigeria meetjidemichael@ymail.com

Faboyede Samuel

FCA, Ph.D., Department of Accounting, Covenant University, Ota, Ogun State, Nigeria samuel.faboyede@covenantuniversity.edu.ng

Babatolu Ayorinde

M.Sc., Department of Accounting, Federal University of Agriculture, Abeokuta, Ogun State, Nigeria ayorinde.tobi@yahoo.com

\section{Doi:10.5901/jesr.2015.v5n1p285}

\begin{abstract}
It is common knowledge that students seek success in examination by attending tuition and training centres to meet teachers that prepare them for the examination. The objective of the tutor is to impart knowledge; the motive of the students is to acquire knowledge, in the easiest possible way. It could happen that a tutor is competent, passionate and willing to teach, while the students are also open, ready, and eager to learn but - in spite of these favourable, positive dispositions to studies by the parties - learning objectives may not be achieved. The study was therefore undertaken to develop a model for evaluating teaching effectiveness in accounting professional programmes using Nigeria as a basis for study. With the aid of questionnaire, we surveyed tutors and students of different accounting professional exams located in south west Nigeria (Lagos and Ogun State). 180 copies of the research instrument were administered; 122 copies-34 from tutors and 88 from students-were retrieved and processed for analyses. The Teaching Effectiveness Index (TEFI) Model had R Square of .850 and ANOVA $p \leq$ .000 ; the model featured five correlates - qualities of a competent tutor, personal teaching style adopted by a tutor, general teaching methods, use of information technology for teaching, and measures enhancing success in exams.
\end{abstract}

Keywords: Accounting, professional exams, Nigeria, students' performances, tuition

\section{Introduction}

It is common knowledge that students seek success in exams by attending tuition/training centres to meet teachers that prepare them for the exam. The objective of the tutor is to impart knowledge; the motive of the students is to acquire knowledge, in the easiest possible way. Renown professional accounting bodies such as; The Institute of Chartered Accountants of Nigeria, ICAN; The Chartered Institute of Management Accountants, CIMA (UK); The Association of Chartered Certified Accountants, ACCA; The American Institute of Certified Public Accountants, CPA, amongst others, recognise the role that tuition providers play in providing the best chances of performance or success for students in professional exams. This explains why they (professional bodies) accredit or designate organisations as recognised training centres, tuition centres, and quality partners.

To some extent, the success of the students is dependent on a tutor; a good tutor should therefore look forward to tutored students exceling in exams. A research conducted by the American Federation of Teachers (2011) on working conditions in American colleges and universities found that most students agree that teachers, tutors, instructors, and professors are positive forces that help students towards success, because the faculty members were involved in the students' learning and success.

It could happen that a tutor is competent, passionate and willing to teach, while the students are also open, ready, and eager to learn but - in spite of these favourable, positive dispositions to studies by the parties - learning objectives may not be achieved, which could be understandably frustrating, unfulfilling, and time-wasting. One of the vagaries that 
may be responsible for such wedge in knowledge transference process is the teaching method.

In our consideration, an examination of teaching methods that brings about effectiveness in tuition delivery and students' performance improvement in professional accounting exams merits research attention. The study was therefore undertaken to develop a model for evaluating Teaching Effectiveness in Accounting professional programmes using Nigeria as a basis for study. Specifically, the study attempts to provide answers to these questions:

(i) How can teaching effectiveness be enhanced in tuition delivery for accounting professional exams?

(ii) What measures can be adopted to improve students' performances in accounting professional exams?

The research hypotheses have been stated, and were tested, in their null forms thus:

$\mathrm{H}^{1}$ : There is no significant difference in the opinion of male and female respondents on the issues of improving tuition and students' performances in accounting professional exams

H02: There is no significant difference in the opinion of tutors and students on the issues of improving tuition and students' performances in accounting professional exams

H03: There is no significant difference in the opinion among tutors and students, whatever their professional affiliation, on the issues of improving tuition and students' performances in accounting professional exams

H04: There is no significant difference in the opinion of tutors of professional exams as to the measures that enhance success in accounting professional exams.

$\mathrm{H} 0^{5}$ : There is no significant difference in the opinion among students of accounting professional exams as to the key performance indicators for teaching effectiveness.

H06. The teaching methods adopted do not significantly affect teaching effectiveness for accounting professional exams

\section{Literature Review}

Pedagogy, which is the use of the appropriate teaching strategy to achieve learning outcome, goes a long way in determining teaching effectiveness and improvement in professional tuition (INTO, 2007; Magiera and Zigmund, 2005). It is therefore crucial for teachers to appraise their teaching strategies per time, in order to identify areas of improvement and make meaningful impact on students.

The teaching style adopted by a tutor is affected to a large extent by the teaching philosophy. Certain questions could help pin-point the teaching philosophy of a tutor, according to Alao (2014), such as; is the teaching interactive and collaborative? Is the tutor hesitant to use a number of teaching styles? Are the students engaged in critical thinking during class? How open is a tutor to suggestions and feedbacks from students?

Literatures on pedagogy and teaching effectiveness (Alao, 2014; Taiwo, 2009; INTO, 2007; NTL institute, 2000) are replete with studies and recommendations that support varying teaching styles by a tutor; expectedly, a good tutor should know how to improve the quality of teaching through varied teaching methods. In this light, INTO (2007) submitted that there are typically three individual learning styles such as: the visual/spatial learners, who like to see what is being taught; the auditory learners, who prefer to hear what is being taught; and the kinaesthetic learners, who like to be physically involved in the teaching process by touching, doing, and feeling. An individual may not exclusively belong to one class but may predominantly display learning attributes of a particular class. Since a tutor is likely to have a class of students with heterogeneous learning styles, it is only appropriate to use a combination of teaching methods.

Also, the NTL institute (2000) recommended that learning should use a combination of approaches because the learning retention rate varies amongst teaching methods. The retention ratio of learning methods is: $5 \%$ in lecture; $10 \%$ in reading; $15 \%$ in visual arts; $30 \%$ in demonstration; $50 \%$ in small group work; $75 \%$ in experimental work; and $90 \%$ in peer tutoring (NTL institute, 2000). Such submissions reiterate the need to combine teaching styles and methods. Methods having a leaning towards students' interactions - such as group assignments, open discussions - have also been noted to bring about teaching effectiveness. Such methods harness the synergistic opportunities presented by exchange of ideas among students with different study styles, background, and assimilation rate Students tend to understand better when they use their language to communicate and learn from one another.

Xiuping (2002) noted that students can concentrate in class only for the first 15 minutes. Some skills and tricks can then be used during teaching, to hold students' attention like: fluctuation of voice (voice pitching), humour or short story (should not be overused), little class exercise, discussions, formulating short mnemonics to help students remember, and communication after class. The role and use of instructional materials in improving professional tuition and enhancing success in exams, have been empirically proven to enhance assimilation and performance (Nsa, lkot and Udo, 2013; Wu, and Chen, 2008). Taiwo (2009) however cautioned that instructional materials should not be seen as a substitute to 
the teacher, because the teacher still has the central responsibility of leading discussions, teaching a subject matter, and stirring the interest of students to embark on further studies beyond what is taught in class. As stated by INTO (2007), it is to be expected that the use of relevant visual materials, audio-visual aids and other learning facilities that are discipline-based can promote effective teaching, because sounds and sights tend to stick quicker and easier to the brain.

Knowledge of the teaching method to use per time before class commencement or while class is on-going is guided by a tutor's experience and intuition, knowledge of students' background, and perceived difficulty in mastering the subject matter (Alao,2014; Taiwo, 2009; Bess, 2000). An effective teacher is able to cut across all types of students, despite unfavourable environmental conditions like distractions, but a conducive environment will cause learning to happen more effectively. Commitment to students, knowledge of the subject taught, pedagogical knowledge, responsibility for managing and monitoring students' learning are some of the characteristics of accomplished teachers as furnished by the National Board for Professional Teaching Standards (1998).

The teacher's competence is main-stream among the vagaries of the knowledge transference process. Miller and Miller (1997) opined that a teacher's competence can be assessed from three standpoints - knowledge of the subject matter, knowledge of pedagogy (instructional planning, delivery and evaluation), and personal traits of the tutor. Personal qualities in a tutor such as; curiosity, tolerance, honesty, fairness, respect, for diversity and appreciation of cultural differences could sustain students' interest in class (Alao, 2014; Friend and Cook, 2003), and such have been found to contribute to teaching effectiveness. The society is known to be dynamic and a tutor that operates in any field of human endeavour must embrace change, continuous improvement, innovation, and openness to new findings, ideas and theories; effective teachers are therefore members of learning committees.

Considering that tutors differ in teaching competences (Bess, 2000), in order to take advantage of the areas where individual tutors have peculiar strength in competence, it is increasingly becoming a common practice to have more than one tutor teach a course (co-teaching). In effect, just as a tutor could use a combination of teaching methods, a course/subject could as well use a combination of tutors to improve teaching effectiveness and students' performances (Friend and Cook, 2003), especially if such opportunities are available, in order that the class can benefit from the uniqueness of the different available teachers. Even co-teaching has its own strategies, as noted by Magiera and Zigmund (2005). One teacher may take the lead role, while others support; an entire class could be split into smaller groups while a tutor is assigned to teach each smaller group, such that classes run concurrently; the course contents could be split into topics to be taught by different tutors. The approach to be selected should however depend on the students' needs, complexities of the subject matter, experience of teacher, and time availability.

To facilitate the knowledge transference process through the teaching method adopted, Alao (2014) suggested some common snags to keep in mind during classes - including avoiding students' solitary silence, anticipating in advance what might go wrong (internet access failures, system crash, sound seizure of electronic devices, or sudden non-functionality of an IT facility) - and having a backup plan to counteract it.

\section{Research Method}

We surveyed tutors and students of different accounting professional exams located in south west Nigeria (Lagos and Ogun State) to obtain their views on four major themes-(i) qualities of a competent tutor, (ii) teaching methods (subdivided into-a tutor's personal teaching style, general teaching methods, and use of Information Technology for lectures), (iii) measures specifically targeted at enhancing success in professional exams, and (iv) performance indicators for measuring teaching effectiveness. These variables were used to develop a teaching effectiveness model. 180 copies of the research instrument were administered; 122 copies-34 from tutors and 88 from students-were retrieved and processed for analyses. Demographic characteristics such as gender, status (tutor/student), professional affiliation (ICAN, CIMA (UK), ACCA, CPA; and Others), and length of experience as tutor/student, were collected and used to analyse responses obtained.

A model was developed for teaching effectiveness index (TEFI) for accounting professional exams thus:

TEFI $=\mu 0+\mu 1 \mathrm{QCT}+\mu 2 \mathrm{PTS}+\mu 3 \mathrm{GTM}+\mu 4 \mathrm{ITM}+\mu 5 \mathrm{SEM}+\varepsilon$ [1]

TEFI-Teaching effectiveness index QCT-Qualities of a competent tutor PTS- Personal teaching style adopted by a tutor GTM- General Teaching Methods ITM- Use of information technology for teaching SEM - measures enhancing success in exams $\mu 0, \mu 1, \mu 2, \mu 3, \mu 4, \mu 5$ - Regressor co-efficients $\varepsilon$ - error term

The Teaching effectiveness index (TEFI) was constructed using regression analysis. Statistics such as Mean (M), T-test, ANOVA and regression were used for analyses. Hypotheses 1, and 2, were tested using the independent sample T-test (assuming non-equality of variances), hypotheses 3, 4 and 5 tested with ANOVA, and hypothesis 6 tested with 
regression analysis. The six hypotheses were evaluated and inferences deduced on the basis of $1 \%$ significance level. The SPSS 17 software was used for all statistical analyses.

\section{Analyses and Discussions}

\subsection{Data presentation and analysis}

Table 1 contains analysis of the qualities of a competent tutor. Four qualities have the highest mean of 4.90 - ability to match theory with practice, technical competence \& authoritativeness, self-confidence, and patience. These are considered threshold qualities of a tutor. Other qualities having a mean score of at least 4.50 (equivalent to $90 \%$ ) are: being up-to-date $(M=4.85)$, class management $(M=4.65)$, communication ability $(M=4.60)$, ability to encourage $(M=4.60)$, passion for teaching $(M=4.55)$, maintaining students' interest $(M=4.55)$, interest in students' progress $(M=4.50)$, and ability to mentor $(M=4.50)$. The other qualities have mean score greater than 3.50 (equivalent to $70 \%$ ), and on this basis, we consider that they are qualities that are important, which contribute to the competence of a tutor.

Table 1: Analysis of response: Qualities of a competent tutor in accounting

\begin{tabular}{lccc}
\hline \hline & Minimum & Maximum & Mean \\
\hline Ability to match theory with practice in the subject/ field & 3 & 5 & 4.90 \\
Technical competence and authoritativeness in the subject/ field & 4 & 5 & 4.90 \\
Self-confidence & 4 & 5 & 4.90 \\
Patience & 4 & 5 & 4.90 \\
Being up-to-date with recent developments in the subject/ field & 4 & 5 & 4.85 \\
Ability to manage and control class & 4 & 5 & 4.65 \\
Ability to communicate effectively, respectfully and authoritatively & 4 & 5 & 4.60 \\
Ability to encourage and inspire confidence in students & 4 & 5 & 4.60 \\
Passion for teaching & 4 & 5 & 4.55 \\
Ability to maintain students' full interest throughout the class & 3 & 5 & 4.55 \\
Interest in students' progress and success & 4 & 5 & 4.50 \\
Ability to mentor & 3 & 5 & 4.50 \\
Ability to manage time by ensuring syllabus coverage & 3 & 5 & 4.30 \\
Thoroughness & 3 & 5 & 4.20 \\
Ability to use Information technology tools for lecture delivery & 3 & 5 & 4.20 \\
Ability to be accessible/ approachable & 3 & 5 & 4.05 \\
Punctuality & 3 & 5 & 4.00 \\
Compassion for students & 3 & 5 & 3.80 \\
Humility & 3 & 5 & 3.75 \\
\hline
\end{tabular}

These qualities do not operate in isolation, as there are interrelationships among them. Being up-to-date in the field will enhance the technical competence of a tutor, while being technically competent should bring about self-confidence. The ability to communicate effectively and authoritatively is expected to ensure effective class management. The passion for teaching, compassion for students, and interest in the progress of students will cause a tutor to be patient to clarify unclear aspects of a topic, which in turn sustains the interest of the students. The ability to match theory with practice, encourage and inspire students should also sustain their interest in the subject. Overall, the qualities reinforce one another.

Table 2: Teaching measures adopted by Tutor

\begin{tabular}{lccc}
\hline \hline & Minimum & Maximum & Mean \\
\hline Getting feedbacks from students on what is taught & 4 & 5 & 4.45 \\
Ability to introduce but balance humour during lectures & 4 & 5 & 4.25 \\
Informal interaction with students & 4 & 5 & 4.25 \\
Assessment of tutor by students & 3 & 5 & 4.10 \\
Providing out-of-class advice & 2 & 5 & 3.65 \\
understanding study style and background of each student & 2 & 5 & 3.65 \\
\hline
\end{tabular}


Teaching methods a tutor could personally adopt are contained in table 2. Getting feedbacks from students $(M=4.45)$ by asking questions in-between/ at end of lectures gives students opportunities to clarify unclear aspects. Introducing humour $(M=4.25)$ to make the class lively could be used to sustain students' interest. Informal interaction with students $(M=4.25)$ makes the tutor approachable. Completing assessment forms by students $(M=4.10)$ could also provide useful feedbacks to tutors on commendations (which provide motivation to the tutor) and areas to be improved. Providing outof-class advice $(M=3.65)$ deepens informal interaction and in turn increases accessibility of tutor to students. Understanding study style and background of each student $(M=3.65)$ informs the tutor on which approach to use to teach the subject.

Table 3: Effective teaching methods

\begin{tabular}{lccc}
\hline \hline & Minimum & Maximum & Mean \\
\hline Combined teaching method & 4 & 5 & 4.95 \\
Giving opportunities for asking questions during lecture & 4 & 5 & 4.75 \\
Use of real-life examples to illustrate points & 4 & 5 & 4.60 \\
Giving class assignments & 4 & 5 & 4.55 \\
Open discussions in class & 4 & 5 & 4.50 \\
Spelling out coverage responsibility between Tutor \& Student & 4 & 5 & 4.50 \\
Eliciting students' expectations at course commencement & 3 & 5 & 4.15 \\
Use of study groups and giving of group assignments & 3 & 5 & 4.10 \\
orienting students at first lecture to manage their expectation & 2 & 5 & 4.05 \\
Observing students' body language to evaluate assimilation rate & 2 & 5 & 4.05 \\
Use of voice pitching and body posture to emphasise key points & 3 & 5 & 3.80 \\
Having short-breaks in-between classes to sustain full attention & 1 & 5 & 3.70 \\
\hline
\end{tabular}

The array of teaching methods is contained in table 3. Giving opportunities for asking questions in-between/ end of lecture as a strategy for ensuring effectiveness in teaching $(M=4.75)$ reinforces the essence of getting feedbacks from students on what is taught. The use of real-life examples to illustrate points $(M=4.60)$ corroborates the ability to match theory with practice in the subject/ field as a threshold quality for an accounting tutor. Other measures such as giving class assignments $(M=4.55)$, group assignments $(M=4.10)$, open discussions in class $(M=4.50)$, spelling out course coverage responsibility $(M=4.50)$ all emphasises the roles students play in ensuring teaching effectiveness and therefore put some level of responsibilities in their hands. Eliciting students' expectations from the course at commencement $(M=4.15)$ helps in properly situating the course objectives to manage their expectations $(M=4.05)$, which consequently serves as guide for responsibility-sharing between tutor and students to achieve course coverage. Observing students' body languages to evaluate assimilation rate $(M=4.05)$, to gauge timing for short-breaks in-between classes $(M=3.70)$, could be used as a means to sustain students' interest in the subject. The use of voice pitching and gesticulation to emphasise key points $(M=3.80)$ is another effective teaching method which helps to avoid students getting bored in class. The combination of teaching methods has highest mean score $(M=4.95)$, suggesting that a tutor should employ a combination of methods to strengthen teaching effectiveness. On the whole, the teaching methods presented in table 3 have minimum mean score of 3.70 (equivalent to $74 \%$ ), and in our reckoning, are effective teaching methods because the weakness of one method is offset by the strength in the other. Also, the methods should address the tuition needs of all students, whatever their learning style. For example, a student who is not fast in grasping what is taught the first time in class, has opportunity to learn from his colleagues during open discussions or group assignments.

Table 4: Use of Information Technology for tuition delivery

\begin{tabular}{lcrc}
\hline \hline & Minimum & Maximum & Mean \\
\hline Use of clear, self-explanatory slides for lectures & 3 & 5 & 4.40 \\
Use of audio-visual materials for lectures & 4 & 5 & 4.25 \\
Use of Information technology for lectures beyond the class & 3 & 5 & 4.20 \\
Logical arrangement of lecture slides in sequential modular form & 3 & 5 & 4.15 \\
\hline
\end{tabular}

In table 4, all the four measures on the use of IT for teaching effectiveness have mean score over 4.0 (equivalent to $80 \%$ ), suggesting that Information technology (IT) can be used to advantage in teaching. IT is changing the manner of 
tuition delivery. Teachers can take advantage of IT to prepare audio-visual lecture materials and deliver lectures. Students can also take advantage of IT for self-study and assessment (online courses, studying by distant learning, online quiz, e-library, etc.), and can also leverage on IT for informal academic interaction with tutors (e.g. e-mails) beyond the classroom.

Table 5: Measures enhancing success in professional exams

\begin{tabular}{lccc}
\hline \hline & Minimum & Maximum & Mean \\
\hline Emphasising mastery of command words used in exams & 4 & 5 & 4.70 \\
Emphasising the need to comply with the examiner's instructions & 3 & 5 & 4.60 \\
Giving incisive feedbacks on assignments/exams assessments & 4 & 5 & 4.55 \\
Specifying major aspects to cover in syllabus & 3 & 5 & 4.55 \\
Enlightening students on time management strategies in exam & 4 & 5 & 4.45 \\
Designing lecture timetable to ensure syllabus coverage & 4 & 5 & 4.40 \\
Writing of professional mock exams & 2 & 5 & 4.30 \\
\hline
\end{tabular}

Analysis of measures specifically targeted at enhancing students' success in accounting professional exams is presented in table 5. Emphasising mastery of command words used in exams has the highest-ranking mean of 4.70 . This is closely followed by emphasising compliance with the examiner's instructions $(M=4.60)$. Understanding and complying with command words used in exam question requirements such as analyse, appraise, define, describe, discuss, evaluate, recommend, etc. is critical for success in accounting professional exams. Writing of mock exams (4.30) and getting feedbacks on performance $(M=4.55)$ helps a tutor in profiling individual students for areas of weakness to be improved upon before the actual exams. Specifying major coverage areas in syllabus $(M=4.55)$ also helps in designing lecture timetable to ensure such major areas are covered $(M=4.40)$. In all, the measures have mean score of 4.3 (representing $86 \%$ on a scale 5 -point scale calibration) and above; we consider that they contribute very significantly to success in accounting professional exams.

Table 6: Key Performance Indicators (KPI) for teaching effectiveness

\begin{tabular}{lccc}
\hline \hline & Minimum & Maximum & Mean \\
\hline Level of understanding subject matter before and after lecture & 4 & 5 & 4.70 \\
Extent to which specified course objectives were met & 4 & 5 & 4.55 \\
Students' willingness to recommend tuition to other students & 3 & 5 & 4.50 \\
Success rates in exam & 2 & 5 & 4.45 \\
Extent to which students expectations were met & 3 & 5 & 4.15 \\
\hline
\end{tabular}

Table 6 shows the different ways of evaluating teaching effectiveness for accounting professional exams. The level of understanding the subject matter before and after the lecture (4.70) is the highest ranking key performance indicator $(\mathrm{KPI})$. This is to be expected because teaching is undertaken essentially to make students understand what is being taught. The level of understanding should therefore reflect how effective the teaching was. To achieve a significant, positive, forward shift in level of understanding of students, there is the need to use different approaches, depending on the cause of hindrance in the knowledge transference process, but would generally include-- pausing to take questions in-between class to ensure students are carried along, sustaining the students' interest, opening discussions in class, giving group assignments, or using a combination of methods. The extent to which course objectives are met, as a measure of assessing teaching effectiveness $(M=4.55)$, reinforces the need to pre-specify course objectives, and manage students' expectations by providing some orientation during the first class. It also emphasises the place of tutorstudent responsibility sharing. Students' willingness to recommend tuition to other students $(M=4.50)$ signals one, some or all of the following-students' satisfaction with achievement of course objectives, teaching method, success rates in exam $(M=4.45)$ or extent of meeting expectations $(M=4.15)$. 


\subsection{Test of Hypotheses}

\subsubsection{Hypothesis 1}

There is no significant difference in the opinion of male and female respondents on the issues of improving tuition and students' performances in accounting professional exams

Table 7: Analysis of views between Male and Female on tuition \& students' performance issues

\begin{tabular}{|c|l|c|c|}
\hline S/N & Issues & P value & Decision at 1\% significance \\
\hline 1. & Qualities of a competent tutor & .021 & Accept Null Hypothesis \\
\hline 2. & Tutor's personal teaching style & .498 & Accept Null Hypothesis \\
\hline 3. & Teaching method & .743 & Accept Null Hypothesis \\
\hline 4. & Use of technology for lecture & .015 & Accept Null Hypothesis \\
\hline 5. & Measures enhancing success in exam & .132 & Accept Null Hypothesis \\
\hline 6. & Teaching effectiveness & .410 & Accept Null Hypothesis \\
\hline
\end{tabular}

Hypothesis 1 examines the opinion of respondents on six issues in the study, analysing differences in views from the gender perspective. The $p$ values for all issues are greater than 0.01 , meaning they are not statistically significant at $1 \%$.We therefore accept the null hypothesis that there is no significant difference in the opinion of male and female respondents on the issues of improving tuition and students' performances in accounting professional exams. This mean that Male and Female respondents are agreed on the qualities of a competent tutor, teaching methods, measures enhancing success in exams, and KPI for teaching effectiveness.

\subsubsection{Hypothesis 2}

There is no significant difference in the opinion of tutors and students on the issues of improving tuition and students' performances in accounting professional exams

Table 8: Analysis of views between Tutors and Students on tuition \& students' performance issues

\begin{tabular}{|c|l|c|c|}
\hline S/N & Issues & P value & Decision at 1\% significance \\
\hline 1. & Qualities of a competent tutor & .364 & Accept Null Hypothesis \\
\hline 2. & Techniques focusing on the tutor & .920 & Accept Null Hypothesis \\
\hline 3. & Teaching method & .682 & Accept Null Hypothesis \\
\hline 4. & Use of technology for lecture & .618 & Accept Null Hypothesis \\
\hline 5. & Measures enhancing success in exam & .016 & Accept Null Hypothesis \\
\hline 6. & Teaching effectiveness & .299 & Accept Null Hypothesis \\
\hline
\end{tabular}

We analysed difference in the opinion of tutors and students of professional exams on the six issues concerning tuition and students performances in professional exams. The $p$ values for all issues are greater than 0.01 , meaning each issue is not statistically significant at $1 \%$. We therefore accept the null hypothesis that there is no significant difference in the opinion of tutors and students on the issues of improving tuition and students' performances in accounting professional exams. This means that Tutors and Students are agreed on the qualities of a competent tutor, teaching methods, and measures enhancing success in exams, and KPI for teaching effectiveness.

\subsubsection{Hypothesis 3}

There is no significant difference in the opinion among tutors and students, whatever their professional affiliation, on the issues of improving tuition and students' performances in accounting professional exams 
Table 9: Analysis of views, as per professional affiliation, on tuition \& students' performance issues

\begin{tabular}{|c|l|c|c|}
\hline S/N & Issues & P value & Decision at 1\% significance \\
\hline 1. & Qualities of a competent tutor & .352 & Accept Null Hypothesis \\
\hline 2. & Techniques focusing on the tutor & .798 & Accept Null Hypothesis \\
\hline 3. & Teaching method & .431 & Accept Null Hypothesis \\
\hline 4. & Use of technology for lecture & .437 & Accept Null Hypothesis \\
\hline 5. & Measures enhancing success in exam & .523 & Accept Null Hypothesis \\
\hline 6. & Teaching effectiveness & .866 & Accept Null Hypothesis \\
\hline
\end{tabular}

We analysed, using professional affiliation, respondents' opinion on the six issues of improving teaching effectiveness and performance. The results of table 9 show $p$ value greater than 0.01 for all issues, meaning the difference in view among respondents is not statistically significant at $1 \%$.We therefore accept the null hypothesis that there is no significant difference in the opinion among tutors and students, whatever their professional affiliation, on the issues of improving tuition and students' performances in accounting professional exams. This implies that the qualities of a competent tutor, teaching methods, and measures enhancing success in exams, and KPI for teaching effectiveness applies to most accounting professional exams (ICAN, ACCA, CIMA,CPA and Others), irrespective of the type.

\subsubsection{Hypothesis 4}

There is no significant difference in the opinion of tutors of professional exams as to the measures that enhance success in accounting professional exams.

Table 10: Analysis of Tutors' views: measures enhancing success in accounting professional exams

\begin{tabular}{|c|c|c|c|}
\hline S/N & Issues & P value & Decision at 1\% significance \\
\hline 5. & Measures enhancing success in exam & .707 & Accept Null Hypothesis \\
\hline
\end{tabular}

We used years of experience as a tutor, (categorized into 1, 2-3, 4-5, and over 5), as the factor analysis to examine opinion among tutors as to measures that enhance success in accounting professional exam in table 10 . With $P$ value of 0.707 greater than 0.01 , we accept the null hypothesis that there is no significant difference in the opinion of tutors of professional exams as to the measures that enhance success in accounting professional exam. In other words, tutors are agreed that the measures in table 5 can be used to enhance students' success in accounting professional exams.

\subsubsection{Hypothesis 5}

There is no significant difference in the opinion among students of accounting professional exams as to the key performance indicators for teaching effectiveness.

Table 11: Analysis of students' views on key performance indicators for teaching effectiveness

\begin{tabular}{|c|c|c|c|}
\hline S/N & Issues & P value & Decision at 1\% significance \\
\hline 6. & Teaching effectiveness & .214 & Accept Null Hypothesis \\
\hline
\end{tabular}

In table 11, we analysed the perception of students of various accounting professional exams on how teaching effectiveness is evaluated. We used number of years as a student of professional exam (in the following categories: 1, 2$3,4-5$, and over 5 ) as the factor. The result shows $p$ value greater than 0.01 , we accept the null hypothesis that there is no significant difference in the opinion among students of accounting professional exams as to the key performance indicators for teaching effectiveness. This means students typically assess teaching effectiveness on the basis of the KPIs in table 6.

\subsubsection{Hypothesis 6}

The teaching methods adopted do not significantly affect teaching effectiveness for accounting professional exams 
Table 12: Regression analysis for Teaching Effectiveness

\begin{tabular}{|c|c|c|c|c|c|c|}
\hline & \multirow{2}{*}{ Model } & \multicolumn{2}{|c|}{ Unstandardized Coefficients } & \multirow{2}{*}{$\frac{\text { Standardized Coefficients }}{\text { Beta }}$} & \multirow{2}{*}{ t } & \multirow{2}{*}{ Sig. } \\
\hline & & $B$ & Std. Error & & & \\
\hline \multirow{6}{*}{1} & (Constant) & -14.369 & 6.024 & & -2.385 & .032 \\
\hline & QCT & .613 & .117 & 1.092 & 5.217 & .000 \\
\hline & PTS & .206 & .174 & .181 & 1.186 & .256 \\
\hline & GTM & 1.498 & .249 & 1.686 & 6.020 & .000 \\
\hline & ITM & .256 & .239 & .150 & 1.070 & 303 \\
\hline & SEM & 1.676 & .221 & 1.593 & 7.592 & .000 \\
\hline
\end{tabular}

a. Dependent Variable: Measurement of Teaching Effectiveness

Model Summary

\begin{tabular}{cccccc}
\hline \hline Model & $\mathrm{R}$ & $\mathrm{R}$ Square & Adjusted R Square & Std. Error of the Estimate & ANOVA P value \\
\hline 1 & $.922^{\mathrm{a}}$ & .850 & .797 & 1.226 & 0.0000 \\
\hline \hline \multicolumn{5}{c}{ a. Predictors: (Constant), QCT, PTS, GTM, ITM, SEM } \\
\hline \hline
\end{tabular}

The result of regression analysis in table 12 shows that the model has an overall ANOVA p-value of 0.000 , meaning the model is statistically significant at $1 \%$. The co-efficient of determination (R Square) is .850 , meaning that of teaching effectiveness is $85 \%$ dependent on the five regressors. The General teaching methods (GTM) has an unstandardized beta coefficient of 1.498 and $p$ value of .000 , which is less than 0.01 , implying statistical significance at $1 \%$. Based on this deduction, we reject the null hypothesis and conclude that the teaching methods adopted do not significantly affect teaching effectiveness for accounting professional exams

From the regression analysis, by substituting the co-efficients in the table 12 in equation 1, the teaching effectiveness index (TEFI) for accounting professional exams becomes:

$T E F I=-14.369+.613 Q C T+.206 P T S+1.498 G T M+.256 / T M+1.676 S E M$ [2]

The acceptance of the null hypotheses 1 to 5 suggest that overall, there are no significant difference in the opinion of respondents when segmented on the basis of gender, status as a tutor or student, and professional affiliation on the six issues studied on improving tuition and students' performances in exams. The results establish the validity and acceptability of analyses of results in tables 1 to 6 .

\section{Concluding Remarks}

There are empirical evidences from this study that teaching effectiveness in accounting professional tuition is a locus of five variables - qualities of a tutor, personal teaching measures adopted by a tutor, general teaching methods, use of information technology for teaching, and success rate in exams.

Virtues such as technical competence and authoritativeness, assertiveness, approachability, patience, selfconfidence, amongst others, contribute to teaching effectiveness. Tutors are therefore encouraged to imbue and/or improve upon these attributes, which we considered as threshold qualities of a professional tutor. Students assimilate easier and more readily when they can relate what they are taught to everyday life - in this light, we suggest the use of teaching methods that blend theory with practice to deepen students' understanding. We also advocate for the utilization of combined teaching methods to ensure that tuition delivery benefits all categories of students, whatever their background or learning styles.

Our results have shown that information technology (IT) contributes to teaching effectiveness. Technology is increasingly and radically changing lecture delivery modes. To maintain relevance as an accounting tutor in the $21^{\text {st }}$ century, possessing IT manoeuvre skills is sacrosanct. Succeeding in both tuition delivery and performance enhancement in professional accountancy exams is the joint responsibility of tutors and students. A cordial relationship between the parties is therefore sine qua non for achieving study objectives. 


\section{References}

Alao A. (2014) Teaching Pedagogy. Workshop on equipping faculty for effective instructional delivery, held at the African Leadership Development Centre (ALDC), Covenant University, Ota, Ogun state

American Federation of Teachers (2011) Exploring Student Attitudes, Aspirations \& Barriers to Success. Retrieved https://www.aft.org/ pdfs/highered/studentfocusgrp0311.pdf

Bess, J. (2000) Integrating autonomous professionals through team teach teaching. In Bess, J L and Associates (eds) Teaching Alone, Teaching Together: Transforming the structure of teams for teaching. 203-235. Jossey-Bass Inc: San Francisco, California.

Friend, M, and Cook, L (2003) Interactions: Collaboration skills for school professionals (4th ed.) Boston: Allyn and Bacon.

INTO (2007) Approaches to Teaching \& Learning, Irish National Teachers' Organization (INTO) Consultative Conference on Education, conference proceedings Retrieved http://www.into.ie/ROI/Publications/ApproachesTeachingandLearning.pdf

Magiera, K, and Zigmund, N (2005) 'Co-teaching in middle school classrooms under routine conditions: Does the instructional experience differ for students with disabilities in co-taught and solo-taught classes?' Learning Disabilities Research and Practice,20(2),79-85

Miller,W.and Miller,M. (1997)Handbook for college teaching, Sautee-Nacoochee,GA: Pinecrest Publications.

Nsa S., Ikot A., and Udo M. (2013) Instructional materials utilization and students' performance in practical agriculture, Journal of Educational Research and Reviews ,1(4), 49-54

NTL Institute (2000). Retention Rates from Different Ways of Learning . Retrieved: http://www.cofc.edu/bellsandwhistles/research/ retentionmodel.html

Taiwo S. (2009) Teachers' perception of the role of media in classroom teaching in secondary school, The Turkish Online Journal of Educational Technology, 8 (1), 75-83

The National Board for Professional Teaching Standards (1998). Washington D.C. Retrieved http://www.nbpts.org

Wu, M. and Chen, S (2008) Elementary schoolteachers' use of instructional materials on the web", Electronic Library, 26 (6), 833 - 843

Xiuping Z (2002) The Combination of Traditional Teaching Method and Problem Based Learning, The China Papers, 1 (1), $30-36$ 